\title{
Emotional and behavioral problems in infants and preschool children: prevalence and sociodemographic risk factors
}

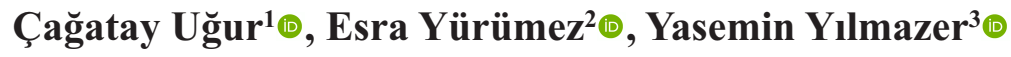 \\ ${ }^{1}$ Department of Child and Adolescent Psychiatry, Ankara Dışkapı Pediatric Hematology Oncology Training and Research Hospital, \\ Ankara, Turkey \\ ${ }^{2}$ Department of Child and Adolescent Psychiatry, Ankara University School of Medicine, Ankara, Turkey \\ ${ }^{3}$ Department of Child and Adolescent Psychiatry, Child Development Unit, Ankara Dışkapı Pediatric Hematology Oncology Training \\ and Research Hospital, Ankara, Turkey
}

DOI: $10.18621 /$ eurj.379887

\begin{abstract}
Objective: To determine the prevalence of behavioral disorders and the relationship between sociodemographic, environmental and family factors among infants and preschool children applied to psychiatry clinic.

Methods: The sample comprised 355 children between 20-59 months of age and showing normal developmental pattern. After psychiatric assessments, the patients were referred to the child development unit for developmental assessment, support and psychoeducation. Ankara Developmental Screening Inventory (ADSI) was applied to all participants.

Results: The mean age was significantly higher among the children applied to the clinic due to limit setting problems (LSP) than that of the children applied due to the other problems. The children with speech delay were the group applied to the clinic at the earliest age. Speech delay rates were higher among boys compared with girls. Sibling jealousy was more common among girls than boys. In the group with LSP, fathers' education levels were lower than that of the group without LSP. There was no difference between children in terms of the number of siblings, birth order and family size.

Conclusion: The findings indicate that limit setting was by far the most common problem among children applied to our clinic. Consequently, the utility of results to raise intervention strategies within limit setting should be developed and intervened earlier.
\end{abstract}

Keywords: Infant, preschool children, limit-setting, emotional problems, behavioral problems

Received: January 17, 2018; Accepted: March 28, 2018; Published Online: April 7, 2018

B agner et al. [1] stated that emotional and behavioral problems are highly prevalent in early childhood and are important focal points for child psychiatrists. While psychiatric disorders traditionally are not diagnosed in children younger than two years of age, studies conducted in the recent past have demonstrated the appropriateness of assessing emotional and behavioral problems during infancy. Family, environmental and sociodemographic factors have been associated with higher risk for behavioral, developmental and mental disorders in infants and preschool children $[2,3]$.

Experts note that the home environment is the main context in which children grow up and develop

Address for correspondence: Esra Yürümez, MD., Ankara University School of Medicine, Department of Child and Adolescent Psychiatry, Cebeci Hospital, Mamak Street, Altındağ, 06230 Ankara, Turkey

E-mail: esrayurumez@gmail.com,Tel.+903125957108 
[4-6]. This being the case, it has a significant influence on the development of behavioral problems. In a family, the interactions between family members have an effect on other family members through the quality of their relationships and personal risk factors which can ultimately spill over and impact on the relationships with other people [7].

A number of studies have shown that low level of parental education, young maternal age, experience of stressful life events and low socio-economic background are associated with increased risk of developing attention, externalizing and internalizing problems among children $[4,8]$.

A number of studies have been conducted on the prevalence of childhood behavioral problems in different countries [9-11]. A review of related studies published in 20 countries revealed prevalence of behavioral problems ranging from 1 to $51 \%$ [12]. Among preschool aged children (between 1-6 years old), the overall prevalence rate was found to be $10 \%$ according to the review. Another review conducted by Brauner and Stephens [13] reported that among children aged less than five, the prevalence rate for behavioral and emotional problems ranged from 9.5 to $14.2 \%$.

In Turkey, studies on the prevalence of behavioral and mental health problems among infants and preschool age children are insufficient. Furthermore, although links between sociodemographic, environmental and family attributes and children's mental health have been established in several studies [1-4], a few studies have been conducted in this area. This study aims to determine the prevalence of behavioral disorders and the link between sociodemographic, environmental and family factors among infants and preschool children applied to an outpatient clinic in Ankara, Turkey.

\section{METHODS}

For the study, the data review of the patients applied to our clinic between April 2016 and January 2017 was conducted. The sample of the study included the patients who applied to the child and adolescent psychiatry clinic and whose semi-structured psychiatric interviews were completed before being referred to the child development unit for developmental support, monitoring and family education.

\section{Participants}

The sample comprised 355 young children between 20 and 59 months of age and their mothers or fathers who applied to an outpatient child development and monitoring unit of a training and research hospital. Children with chronic medical or neurological disease, intellectual and developmental delay (except for those who only have speech delay), uncorrected visual and auditory problems were excluded.

\section{Procedure}

The research protocol was approved by the local ethic committee. The procedures of the study were in accordance with the Declaration of Helsinki, as well as local laws and regulations. The developmental stages of the children were assessed using the Ankara Developmental Screening Inventory (ADSI), and the children who showed normal developmental pattern were included in the study.

\section{Measures \\ Sociodemographic form}

A questionnaire comprised queries on the perinatal and developmental history of child, age, education levels, occupation, number of children, physical and mental illnesses, marital status (married, divorced or widowed) of parents, social support of the family and other family members was used.

\section{Ankara Developmental Screening Inventory (ADSI)}

The ADSI is a 154-item scale based on a parental report for the assessment and evaluation of social, cognitive and communicative levels of children between 0-6 years of age [14]. The five subscales of the inventory are language-cognitive, fine motor, gross motor, social interaction skills and self-care abilities. The internal consistency of the scale was $.99-80$ and the test-retest reliability values were $.99-.80$ for three age groups (0-12, 13-44 and 45-72 months).

\section{Statistical Analysis}

SPSS 17.0 was used for analyses. Categorical variables were pointed out with frequency (n) and 
percentages (\%). Continuous variables were highlighted by mean, median, standard deviation and range. Chi-square and Fisher's exact test, t-test were used where appropriate. The value of $p<0.05$ was accepted as statistically significant.

\section{RESULTS}

A total of 355 subjects were included in the study. Among all children, 126 (35.4\%) were in early childhood (20-36 months) and 229 (64.5\%) were in preschool age (36-59 months).

The mean age of the participants was $40 \pm 10$ months. The mean age of the children with speech delay was $35 \pm 9.6$ months. The children with speech delay were the group who applied to the clinic at the earliest age. In all participants, 208 patients $(58.5 \%)$ were males and 147 (41.4\%) were females. Mothers' mean age was $30.9 \pm 5.1$ years, and fathers' mean age was $34.6 \pm 5.4$ years. The maternal and paternal average education durations were $10.2 \pm 3.5$ and 11.8 \pm 3.1 years, respectively.

\section{The frequency of causes of admission}

Patients included in the study had various reasons for referring to the hospital. The main reason of admission was limit setting problems (229 children,
$64.5 \%$ ). The frequency distributions of causes of admission were shown in Table 1.

\section{Gender comparisons}

As a reason for referring to the hospital, the speech delay was more common among boys than girls $(21.2 \%$ vs. $10.4 \%)$. Sibling jealousy was a significantly more frequent reason among girls than boys $(9.8 \%$ vs. $4.8 \%)$ as shown in Table 1.

\section{Number of siblings}

The family sizes and number of siblings were analyzed, 140 (39.4\%) children had no sibling whereas $156(43.9 \%)$ had only one, and 59 (16.7\%) had at least two siblings. Analyzing the relationship between behavioral problems and number of siblings, it was found that prevalence of toilet problems $(67.56 \%)$ were higher among children who had no siblings, than that of children with siblings and this association was statistically significant $(p<0.05)$. It was also found that children without siblings had higher prevalence of eating $(9.2 \%)$ and sleeping problems $(10.7 \%)$ but these associations were statistically not significant $(p>0.05)$. The children having one sibling had higher prevalence of limit setting problems (43.73\%), sibling jealousy (75.86\%), nail eating $(14.1 \%)$ speech disorder $(6.6 \%)$ and masturbation problems $(7.5 \%)$ compared with

Table 1. Frequency and gender comparison of complaints caused application to the clinic.

\begin{tabular}{|c|c|c|c|c|c|}
\hline & $\begin{array}{c}\text { Boys } \\
(n=208)\end{array}$ & $\begin{array}{c}\text { Girls } \\
(n=147)\end{array}$ & $\begin{array}{c}\text { Total } \\
(n=355)\end{array}$ & $\mathbf{X}^{2}$ & $p$ value \\
\hline Limit setting problems & $135(64.9 \%)$ & $94(48.7 \%)$ & $229(64.5 \%)$ & 1.853 & 0.470 \\
\hline Speech delay & $44(21.2 \%)$ & $20(10.4 \%)$ & $64(18.0 \%)$ & 1.068 & 0.045 \\
\hline Toilet habit problems & $23(11.1 \%)$ & $14(7.3 \%)$ & $37(10.4 \%)$ & 1.641 & 0.389 \\
\hline Sibling jealousy & $10(4.8 \%)$ & $19(9.8 \%)$ & $29(8.2 \%)$ & 1.006 & 0.006 \\
\hline Sleep problems & $10(4.8 \%)$ & $11(5.7 \%)$ & $21(5.9 \%)$ & 1.293 & 0.204 \\
\hline Eating problems & $11(5.3 \%)$ & $10(5.2 \%)$ & $21(5.9 \%)$ & 1.551 & 0.353 \\
\hline Nail biting & $8(3.9 \%)$ & $7(3.6 \%)$ & $15(4.2 \%)$ & 1.673 & 0.433 \\
\hline Anxiety & $7(3.4 \%)$ & $5(2.6 \%)$ & $12(3.4 \%)$ & 1.985 & 0.603 \\
\hline Speech disorder & $6(2.9 \%)$ & $3(1.5 \%)$ & $9(2.5 \%)$ & 1.618 & $0.446^{*}$ \\
\hline ADHD signs & $4(1.9 \%)$ & $2(1.0 \%)$ & $6(1.7 \%)$ & 1.205 & 0.197 \\
\hline Divorcing & $3(1.4 \%)$ & $2(1.0 \%)$ & $5(1.4 \%)$ & 1.949 & 0.659 \\
\hline Masturbation & $2(1.0 \%)$ & $2(1.0 \%)$ & $4(1.1 \%)$ & 1.726 & $0.550 *$ \\
\hline Loss of parents & $1(0.5 \%)$ & $2(1.0 \%)$ & $3(0.8 \%)$ & 1.372 & $0.372 *$ \\
\hline Autism & $1(0.5 \%)$ & $1(0.5 \%)$ & $2(0.6 \%)$ & 1.805 & $0.657 *$ \\
\hline Delectation & 0 & $1(0.5 \%)$ & $1(0.3 \%)$ & 1.234 & $0.414 *$ \\
\hline
\end{tabular}

Data are shown as number $(\%)$. ADHD = Attention Deficit Hyperactivity Disorder, $*=$ Fisher's exact test 
Table 2. Demographical and clinical findings of children with limit setting problems

\begin{tabular}{|c|c|c|c|c|c|}
\hline Variables & $\begin{array}{c}\text { Children with } \\
\text { LSP } \\
(n=229) \\
\end{array}$ & $\begin{array}{c}\text { Children without } \\
\text { LSP } \\
(\mathrm{n}=\mathbf{1 2 6}) \\
\end{array}$ & $\begin{array}{c}\text { Total } \\
(n=355)\end{array}$ & $\mathbf{X}^{2}$ & $p$ value \\
\hline \multicolumn{6}{|l|}{ Children } \\
\hline Age (months) & $41 \pm 9.8(20-59)$ & $38.3 \pm 10.2(22-59)$ & $40 \pm 10(20-59)$ & 2.434 & 0.015 \\
\hline Gender & & & & 1.853 & 0.470 \\
\hline Boys & $135(59 \%)$ & $73(57.9 \%)$ & $208(58.6 \%)$ & & \\
\hline Girls & $94(41 \%)$ & $53(42.1 \%)$ & $147(41.4 \%)$ & & \\
\hline \multicolumn{6}{|l|}{ Mothers } \\
\hline age (years) & $31.1 \pm 5.3(19-49)$ & $30.8 \pm 4.8(18-42)$ & $31 \pm 5.1(18-49)$ & 1.446 & 0.505 \\
\hline education (years) & $10.4 \pm 3.3(5-15)$ & $10.3 \pm 3.2(5-15)$ & & 1.446 & 0.505 \\
\hline \multicolumn{6}{|l|}{ Fathers } \\
\hline age (years) & $34.9 \pm 5.6(20-65)$ & $34.3 \pm 5.1(25-55)$ & $34.7 \pm 5.5(20-65)$ & 1.446 & 0.284 \\
\hline education (years) & $9.3 \pm 3.1(5-15)$ & $10.1 \pm 3.1(5-15)$ & & 1.446 & $<0.001$ \\
\hline
\end{tabular}

Data are shown as mean \pm standard deviation (minimum-maximum) or number $(\%)$. LSP $=$ Limit Setting Problems

children without sibling or with more than one sibling. Only sibling jealousy was statistically significant $(p<$ $0.05)$.

\section{Marital status}

The number of parents divorced was $32(9 \%)$ and widowed was $6(1.7 \%)$. The number of children whose parents were married was $310(87.3 \%)$ and children with parents in prison were $7(2 \%)$. There was found no significant association between marital status and the frequency of reasons for admission $(p>0.05)$.

\section{Family type}

The family types were assessed as nuclear (comprised of parents and children) and extended (including other relatives like grandparents living with family) ones. The number of nuclear families was 282 (79.4\%) and extended families was 73 (21.6\%). There was found no significant relationship between family type and problems causing the admission to the clinic $(p>0.05)$.

\section{Results in children with limit setting problems}

A statistical evaluation has also been carried out for the limit setting problems which constitutes more than half of the complaints caused the admission to the hospital.

At this stage, the participants were divided into two groups according to the presence of limit setting problems. Mean age of the children with and without limit setting problems were $41 \pm 9.8$ and $38.3 \pm 10.2$ months, respectively. There was found a significant difference between groups in respect to age at the time of admission ( $p=0.015)$.

Among the children with limit setting problems, $135(58.9 \%)$ patients were males and 94 (41.1\%) were females. In the other group, 73 (57.9\%) patients were males and $53(42.1 \%)$ were females. There was no significant difference between the two groups in terms of distribution of gender $(p>0.05)$.

Mothers' mean age was $31.1 \pm 5.3$ years, and fathers' mean age was $34.9 \pm 5.6$ years. The average education duration of mothers and fathers were 10.7 and 11.3 years respectively. There was found significant difference between groups in fathers' education durations. The education durations of fathers were significantly lower in the group with limit setting problems than the group without limit setting problems $(p<0.001)$ (see Table 2). Sociodemographic features of children were shown in Table 2.

There was found no significant difference between groups with and without limit setting problems in terms of being an only child, birth order and overall family size $(p<0.05)$.

\section{DISCUSSION}

\section{Prevalence of behavioral problems}

The findings of this study indicate that limit 
setting problems, speech delay, toilet habit problems, jealousy of siblings, sleep problems, eating problems, nail eating/finger sucking, anxiety problems, divorcerelated issues, and speech disorder were the most prevalent behavioral problems among infants and preschool children. Limit setting was by far the most common problem among children and followed by speech delay, toilet habit problems, sibling jealousy, and sleep problems. The participants of the current study were composed of patients presented to the clinic. Thus, the results of community screening may differ. On the other hand, these results are widely consistent with those found in past studies. Petersen et al. [15] reported that the prevalence of developmental and behavioral disorders in children (6 months to 17 years) was $33.5 \%$.

Several studies have shown that prevalence rates for insomnia in the United States and Caucasian countries vary from 20 to $30 \%[16,17]$. The frequency of sleep problems was found as $6.0 \%$ in our population. Different from the studies investigating the prevalence of sleep problems specifically, the participants were not assessed in terms of sleep patterns and problems separately. Sleep problems are known to be expressed inadequately if they have not been asked specifically and the frequency of sleep problems may have seen less [18].

In Taiwan, Chou [19] revealed a prevalence of limit setting problems of $70 \%$ and sleep problems of $66 \%$. The prevalence rates for constipation and toilet habit problems in children worldwide stands at between 0.3 to $28 \%[20,21]$. The definition and perception of behavioral problems may differ according to sociocultural environment but generally these results are showing consistency.

\section{Age and Gender}

The average age of children with limit setting problems was statistically older than that of the group without limit setting problems. In addition, most of children with limit setting problems were admitted to the clinic at preschool age. The reason for late admission to the clinic may be normalization of behavioral problems by parents related with cultural norms and approaches in the way of limit setting. Additionally, some parents' may fail to recognize the emotional and behavioral problems until the involvement of children to a structured social environment. Parenting with appropriate limit setting strategies positively influences self-regulation and compliance skills of children [22]. This is related to awareness of social approval or disapproval. Children between 36-60 months are expected to be more compliant by their parents [23]. Starting kindergarten, at the age of 36 months, promotes socialization by an imitative process. Most children will learn to deal with social rules of people who are not family members. They are expected to regulate themselves and meet changing situational demands. The maladaptation of children to parental limit setting may prompt the need for professional intervention in preschool.

In the current study, the children who applied to the clinic due to speech disorders were the youngest group. It is not surprising as speech delay is one of the most worrying and noticeable problems for families. According to the results of this study, female gender is associated with jealousy of siblings. This finding contradicts with a study [24] that showed jealousy of siblings, as expressed in the form of sibling victimization, was more prevalent in boys compared to girls. On the issue of gender effect on sibling jealousy, results of studies are inconsistent. There are studies suggesting that aggressive behaviors of boys and anxious responses of girls increase based on sibling jealousy $[25,26]$. The aggressive behaviors may not be interpreted as the signs of sibling jealousy by parents but it may be easier to link the symptoms like withdrawal, regression, anxiety to jealousy and to seek professional help.

Gender was also found to be associated with speech delay with higher prevalence among boys. This result is consistent with the findings of a study [27] that associated male gender, family history, and low parental education with speech delay problems in children aged five and younger. The findings are also consistent with several previous studies that showed consistent advantage for infant and preschool girls with regard to different aspects of learning including vocabulary size, syntax complexity, vocabulary growth and morphosyntactic growth [28-30]. The advantage that girls enjoy with regard to language learning according to Nelson [31] may be attributed to the fact that they are "left brain dominant learners and therefore analyze speech streams into individual phonetic elements and words". Boys on the other hand, tend to be right brain dominant learners and 
focus more on the overall sound of the language and how it is used.

\section{Parental Age and Education}

In the study, in all children, both the mothers and fathers of children with behavioral and emotional problems were roughly corresponding to young adults. Several studies indicate that children whose parents (mostly mothers) are older, show lower risk of behavioral problems [32]. Other studies, though supporting the link between parental age and disorders, note that for other psychiatric illnesses, this relationship is either unconvincing or inconsistent. Maternal age has a complex link with several psychosocial variables.

Parental education is closely linked to family socio-economic status to the extent that low parental education most often translates to low socio-economic family status and strain on family resources [33]. In the group with limit setting problems, the level of education of the fathers was statistically significantly lower than that of the group without limit setting problems. In terms of maternal education, there was found no significance between two groups but average education level of all mothers which is known to be a risk factor for emerging of psychopathology among children [34] were relatively low in our study. Taking into account that most of the mothers in these families are not being in a job and having a regular income, the socio-economic status of these families may not be high.

\section{Being an Only Child}

The study found an insignificant association between being an only child in the family and having toilet problems. Children who were an only child in their family experienced higher prevalence of divorcerelated problems compared to their counterparts who had siblings. The findings of the study also indicate that children from families with more than three children tended to experience lower prevalence of behavioral problems. Besides that, children without siblings tend to show higher prevalence of toilet habit problems, eating, sleeping, ADHD, speech delay and divorce-related problems. The frequency of emotional and behavioral problems among children without a sibling may be related with experiencing more common parental psychopathology, marital conflicts and separation of parents during growing up. Those who came from families with two children, on the other hand, have higher prevalence of limit setting problems, sibling jealousy, nail eating, speech disorder and masturbation problems. These findings seem to suggest that large families serve as a protective factor against behavioral problems. The results of this study are congruent with the findings of a study [35] that showed higher prevalence of behavioral problems among "only children" and lowest prevalence among large families with at least 3 children. Larger families generally tend to provide children with an environment for socializing which is beneficial for child development [36].

\section{Family Type}

An association (but not significant) was found between family type and eating and divorce-related problems. Children who came from nuclear families had higher prevalence of behavioral disorders compared to their counterparts from extended family. These findings are well in line with the findings of several studies. A study by Taanila and colleagues [35] revealed, for example, that single parent families were associated with increased risk of emotional problems among girls. McLanahan and Sandefur [38] noted that children from single parent families are more likely to experience behavioral problems compared to the children who come from families with two parents. Families with single parents may not provide the stimulating environment for exploration and learning which are necessary for child development. Furthermore, parental stress and depression may affect the child leading to loss of appetite and other eating disorders.

\section{Others}

Contrary to expectation, the study found no significant association between overall family size, parents' marital status traditionally thought to be risk factors for mental and behavioral problems [4, 8]. Several studies have associated parental marital status with behavioral problems to the extent that children coming from families in which the parents are married and more educated show less prevalence of behavioral disorders [39-41]. This situation could be attributed the quality of relationship that parents have with each other and their child consistent with family systems 
theory. The situation could also be explained by the effect of environmental and socio-economic factors such as poverty, unemployment and low parental education.

\section{Limitations}

The relatively large sample size and inclusion of children at normal developmental stages are the strong aspects of our study. On the other hand, one of the limitations of current study is the absence of a control group comprised of healthy children have not applied to a clinic. As rapid improvement or impairments may occur in developmental stages of the preschool age, including a follow up period could give more clear findings.

\section{CONCLUSION}

In terms of assessing the common reasons that infants and preschool children are admitted to the clinic, our study revealed some inferences. The findings indicate that limit setting was by far the most common problem. Insufficient materials assessing parental limit setting problems, inadequate education and training approaches, and lack of studies complicate the development of new intervention strategies in this area. Consequently, the utility of results to produce different approaches, including psychoeducation and supports to the parents with limit setting, should be developed and intervention provided earlier.

\section{Conflict of interest}

The authors disclosed no conflict of interest during the preparation or publication of this manuscript.

\section{Financing}

The authors disclosed that they did not receive any grant during conduction or writing of this study.

\section{REFERENCES}

[1] Bagner D, Rodríguez G, Blake C, Linares D, Carter A. Assessment of behavioural and emotional problems in infancy: a systematic review. Clin Child Fam Psychol Rev 2012;15:113-28.

[2] National Research Council and Institute of Medicine. Preventing mental, emotional, and behavioural disorders among young people: progress and possibilities, The National Academic Press: Washington, 2009.

[3] Evans G, Kim P. Childhood poverty, chronic stress, self-regulation, and coping. Child Dev Perspect 2013;7:43-8.

[4] Santos LMD, Queirós FC, Barreto ML, Santos DND. Prevalence of behaviour problems and associated factors in preschool children from the city of Salvador, state of Bahia, Brazil. Rev Bras Psiquiatr 2016;38:46-52.

[5] Wamboldt M, Cordaro A, Clarke D. Parent-child relational problem: field trial results, changes in DSM-5, and proposed changes for ICD-11. Fam Process 2015;54:33-47.

[6] Bernet W, Wamboldt M, Narrow W. Child affected by parental relationship distress. J Am Acad Child Adolesc Psychiatry 2016;55:5719 .

[7] Coley R, Hernandez D. Predictors of paternal involvement for resident and nonresident low-income fathers. Dev Psychol 2006;42:1041-56.

[8] Ellajosyula R, Narayanan J. Sociodemographic factors, clinical features and course in frontotemporal dementia: a large cohort study from South India. Neurology 2017;88 (16 Suplement):P4.188.

[9] Matijasevich A, Murray E, Stein A, Anselmi L, Menezes AM, Santos IS, et al. Increase in child behaviour problems among urban Brazilian 4-year olds: 1993 and 2004 Pelotas birth cohorts. J Child Psychol Psychiatry 2014;55:1125-34.

[10] Vitolo YL, Fleitlich-Bilyk B, Goodman R, Bordin IA. Parental beliefs and child-rearing attitudes and mental health problems among school children. Rev Saude Publica 2005;39:716-24.

[11] Moren-Cross JL, Wright DR, LaGory M, Lanzi RG. Perceived neighborhood characteristics and problem behaviour among disadvantaged children. Child Psychiatry Hum Dev 2005;36:273-94.

[12] Roberts R, Attkisson C, Rosenblatt A. Prevalence of psychopathology among children and adolescents. Am J Psychiatry1998;155:715-25.

[13] Brauner C, Stephens B. Estimating the prevalence of early childhood serious emotional/behavioural disorders: challenges and recommendations. Public Health Rep 2006;121:303-10.

[14] Savaşır I, Sezgin N, Erol N. [Handbook of Ankara Developmental Screening Test]. Ankara, Turkey: Ankara University School of Medicine; 1994. [Book in Turkish]

[15] Petersen M, Kube D, Whitaker T, Graff J, Palmer F. Prevalence of developmental and behavioural disorders in a pediatric hospital. Pediatrics 2009;123:e490-5.

[16] Calhoun SL, Fernandez-Mendoza J, Vgontzas AN, Liao D, Bixler EO. Prevalence of insomnia symptoms in a general population sample of young children and preadolescents: gender effects. Sleep Med 2014;15:91-5.

[17] Fricke-Oerkermann L, Plück J, Schredl M, Heinz K, Mitschke A, Wiater A, et al. Prevalence and course of sleep problems in childhood. Sleep 2007;30:1371-7.

[18] Mindell JA, Moline ML, Zendell SM, Brown LM, Fry JM. Pediatricians and sleep disorders: training and practice. Pediatrics 1994;94:194-200.

[19] Chou Y. Survey of sleep in infants and young children in northern Taiwan. Sleep Biol Rhythms 2007;5:40-9.

[20] Catto-Smith A. Constipation and toileting issues in children. Med J Aust 2005;182:242-6.

[21] Xinias I, Mavroudi A. Constipation in childhood. An update on evaluation and management. Hippokratia 2015;19:11-9.

[22] Bryant BK, Crockenberg SB. Correlates and dimensions of prosocial behaviour: A study of female siblings with their mothers. Child Dev 1980:529-44.

[23] Stipek D, RecchiaS, McClintic S. Self-evaluation in young children. Monogr Soc Res Child Dev 1992;57:1-98.

[24] Tucker C, Finkelhor D, Shattuck N, Turner H. Prevalence and 
correlates of sibling victimization types. Child Abuse Negl 2013;37:21323.

[25] Shaw DS, Keenan K, Vondra JI. Developmental precursors of externalizing behaviour; Ages 1 to 3. Dev Psychol 1994;30:355-64.

[26] Zahn-Waxler C, Shirtcliff EA, Marceau K. Disorders of childhood and adolescence: Gender and psychopathology. Annu Rev Clin Psychol 2008;4:275-303.

[27] Wallace IF, Berkman ND, Watson LR, Coyne-Beasley T, Wood CT, Cullen K, et al. Screening for speech and language delay in children 5 years old and younger: a systematic review. Pediatrics 2015;136:e44862.

[28] Hadley PA, Rispoli M, Fitzgerald C, Bahnsen A. Predictors of morphosyntactic growth in typically developing toddlers: contributions of parent input and child sex. J Speech Lang Hear Res 2011;54:549-66. [29] Simonsen H, Kristoffersen K, Bleses D, Wehberg S, Jergensen R. The Norwegian Communicative Development Inventories: Reliability, main developmental trends and gender differences. First Language 2014;34:3-23.

[30]Westerlund M, Lagerberg D. Expressive vocabulary in 18-monthold children in relation to demographic factors, mother and child characteristics, communication style and shared reading. Child Care Health Dev 2008;34:257-66.

[31] Nelson K. The nominal shift in semantic-syntactic development. Cogn Psychol 1975;7:461-79.

[32] Tearne J. Older maternal age and child behavioural and cognitive outcomes: a review of the literature. Fertil Steril 2015;103:1381-91.
[33] Ryan RM, Claessens A, Markowitz AJ. Associations between family structure change and child behaviour problems: The moderating effect of family income. Child Dev 2015;86:112-27.

[34] Biedel DC, Turner SM. At risk for anxiety: I. Psychopathology in the offsprings of anxious parents. J Am Acad Child Adolesc Psychiatry 1997;36:918-24

[35] Taanila A, Ebeling H, Kotimaa A, Moilanen I, Järvelin MR. Is a large family a protective factor against behavioural and emotional problems at the age of 8 years?.Acta Paediatr 2004;93:508-17.

[36] Carlson M, Corcoran M. Family structure and children'sbBehavioural andcCognitive outcomes. J Marriage Fam 2001;63:779-92.

[37] Lawson D, Mace R. Siblings and childhood mental health: evidence for a later-born advantage. Soc Sci Med 2010;70:2061-9.

[38] McLanahan S, Sandefur G. Growing Up with a Single Parent. What Hurts, What Helps. Harvard University Press: Cambridge, 1997.

[39] Campbell S, Shaw D, Gilliom M. Early externalizing behaviour problems: toddlers and preschoolers at risk for later maladjustment. Dev Psychopathol 2000;12:467-88.

[40] Tremblay R, Nagin D, Seguin J, Zoccolillo M, Zelazo P, Boivin M, et al. Physical aggression during early childhood: trajectories and predictors. Pediatrics 2004;114:e43-50.

[41] Cote S, Vaillancourt T, LeBlanc J, Nagin D, Tremblay E. The development of physical aggression from toddlerhood to preadolescence: a nationwide longitudinal study of Canadian children. J Abnorm Child Psychol 2006;34:71-85. 